Nicholas J. Moore

\title{
Repetition in Hebrews
}

Plurality and Singularity in the Letter to the Hebrews, Its Ancient Context, and the Early Church

[Wiederholungen im Hebräerbrief. Pluralität und Singularität im Brief an die Hebräer, in seinem antiken Kontext und in der frühen Kirche.]

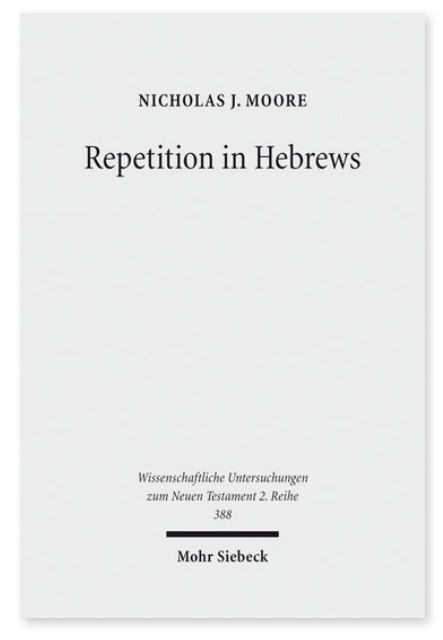

2015. XV, 276 Seiten. WUNT II 388

ISBN 978-3-16-153855-1

DOI 10.1628/978-3-16-153855-1

eBook PDF 109,00€

ISBN 978-3-16-153852-0

fadengeheftete Broschur 109,00€
Veröffentlicht auf Englisch.

Wiederholung hat in der Geschichte des Christentums eine kontroverse und oftmals negative Rezeption erfahren, vor allem in Verbindung mit Ritualen und Liturgie, und der Hebräerbrief liegt diesem strittigen Verständnis zugrunde. Nicholas Moore zeigt, dass die Wiederholungen im Brief an die Hebräer nicht im einheitlichen Kontrast zum einmaligen Tode Jesu für die Menschheit stehen, sondern eher auf verschiedene Art und Weisen fungieren, viele davon konstruktiv. Die Einzigartigkeit des Christusereignisses wird mit Bezug auf den jährlich stattfindenden Versöhnungstag erläutert, um die alles übertreffende theologische Erfüllung auszudrücken, wobei Wiederholungen mit diesem einzigartigen Ereignis kontrastieren oder koexistieren können. Moore zeigt im Einzelnen auf, dass die täglichen levitischen Opfer den fortwährenden christlichen Zugang zu und die Anbetung von Gott andeuten. Diese Neubewertung des Phänomens der Wiederholung im Hebräerbrief bildet die Basis einer erneuerten Wertschätzung ihrer Bedeutung für den theologischen Diskurs und das religiöse Leben.

Nicholas J. Moore Born 1984; 2014 DPhil (Oxon); 2014-17 Assistant Curate, All Saints' Church, Stranton, Hartlepool; since 2017 Tutor, Cranmer Hall, St John's College, Durham.

Jetzt bestellen:

https://mohrsiebeck.com/buch/repetition-in-hebrews-9783161538551?no_cache=1

order@mohrsiebeck.com

Telefon: +49 (0)7071-923-17

Telefax: $+49(0) 7071-51104$ 